\title{
Peroxymonosulfate improves the activity and stability of manganese oxide for oxidation of arsenite to arsenate
}

\author{
by Liu, Y., Zhang, F., Hou, J. and Hartley, W
}

Copyright, publisher and additional information: this is the author accepted manuscript. The final published version (version of record) is available online via Wiley. This article may be used for non-commercial purposes in accordance with Wiley Terms and Conditions for Self-Archiving.

Please refer to any applicable terms of use of the publisher.

DOI: https://doi.org/10.1002/clen.201900195 
Peroxymonosulfate improves the activity and stability of manganese oxide for oxidation of arsenite to arsenate

Yong Liu ${ }^{1}$, Fen Zhang ${ }^{1}$, Jingtao Hou $^{2} *$, and William Hartley ${ }^{3}$

${ }^{1}$ School of Environmental and Biological Engineering, Wuhan Technology and Business University, Wuhan, China

${ }^{2}$ College of Resources and Environment, Huazhong Agricultural University, Wuhan, China

${ }^{3}$ Crop and Environment Sciences Department, Harper Adams University, Newport, Shropshire, United Kingdom

Correspondence: Dr. J. Hou, College of Resources and Environment, Huazhong Agricultural University, Wuhan, 430070, China

Email: houjt87@163.com

\begin{abstract}
Manganese oxide has been widely investigated for oxidation of arsenite (As(III)) to arsenate (As(V)) due to its high redox potential, however it becomes extremely unstable after reuse. Here, As(III) oxidation activity and stability of manganese oxide in the presence of peroxymonosulfate (PMS) was investigated. Batch experimental results revealed that manganese oxide/PMS exhibits high catalytic activity for As(III) oxidation compared to manganese oxide or PMS alone. Addition of PMS to manganese oxide not only revealed long-term stability for
\end{abstract} Received: 17/05/2019; Revised: 18/11/2019; Accepted: 09/12/2019

This article has been accepted for publication and undergone full peer review but has not been through the copyediting, typesetting, pagination and proofreading process, which may lead to differences between this version and the Version of Record. Please cite this article as doi: 10.1002/clen.201900195.

This article is protected by copyright. All rights reserved. 
As(III) oxidation, but also showed high As(III) oxidation activity in the presence of coexisting ions such as As $(\mathrm{V})$ and phosphate. Quenching tests revealed that As(III) oxidation in the manganese oxide/PMS system was attributed to activation of PMS by manganese oxide at different oxidation states (Mn(III) and $\mathrm{Mn}(\mathrm{IV}))$, and the generation of sulfate radicals that were responsible for As(III) oxidation.

Abbreviations: BET, Brunauer - Emmett - Teller; EtOH, ethanol; FTIR, Fourier transform infrared; ICP/OES, inductively coupled plasma/optical emission spectroscopy; PMS, peroxymonosulfate; TBA, tert-butyl alcohol; TEM, transmission electron microscopy; XPS, X-ray photoelectron spectrometry; XRD, X-ray diffraction

Keywords: Activation, Arsenite oxidation, Manganese oxide, Peroxymonosulfate, Sulfate radicals

\section{Introduction}

Arsenic (As) is a common toxic metalloid and has been found at hazardous levels in drinking water throughout the world, especially in South and Southeast Asia ${ }^{[1]}$. It is reported that the groundwater used for drinking by about 140 million people worldwide contains unsafe levels of arsenic ${ }^{[2]}$. As the main exposure to inorganic arsenic for the general population is through ingestion, acquisition of safe drinking water is extremely important for human health ${ }^{[3]}$. With the increasing use of groundwater for drinking purpose, developing effective treatment technologies for reducing the arsenic levels below the WHO standard in groundwater is of great importance. Arsenite $(\mathrm{As}(\mathrm{III}))$ and arsenate $(\mathrm{As}(\mathrm{V}))$ are the two main dissolved As species that exist in polluted groundwater. Between them, As(III) is reportedly more harmful than $\mathrm{As}(\mathrm{V})$ due to its greater mobility and toxicity ${ }^{[4]}$. Therefore, oxidation of $\operatorname{As}(\mathrm{III})$ to $\mathrm{As}(\mathrm{V})$ is not only a possible approach to reducing arsenic impacts on human health, but also is a vital step for total arsenic immobilization prior to treatment by subsequent technologies such as sorption and coprecipitation ${ }^{[5]}$.

Manganese oxide has been widely used for rapid oxidation of $\mathrm{As}(\mathrm{III})$ to $\mathrm{As}(\mathrm{V})$ due to its high redox potential of $E_{0}\left(\mathrm{MnO}_{2} / \mathrm{Mn}^{2+}\right)=1.22 \mathrm{~V}^{[6-15]}$. However, to our knowledge, manganese oxide is unstable after being reused for 
As(III) oxidation, which is attributed to the release of $\mathrm{Mn}^{2+}$ during As(III) oxidation and a decrease in the $\mathrm{Mn}$ oxidation state ${ }^{[8,9]}$. This means that manganese oxide only acts as an oxidant for As(III) oxidation, rather than as a catalyst. In addition, a reduction in oxidation activity may occur in the presence of coexisting ions such as phosphate in arsenic-containing wastewater ${ }^{[14-17]}$. This is due to the favorable adsorption of coexisting ions onto manganese oxide surfaces, which then occupy and passivate its surface active sites ${ }^{[16]}$. Therefore, a strategy to improve As(III) oxidation rate and guarantee the recycling of manganese oxide activity is still required.

Peroxymonosulfate ( $\mathrm{HSO}_{5}^{--}, \mathrm{PMS}$ ) is one form of peroxosulfate-based chemicals that has been widely used as an oxidant in different advanced oxidation process (AOP) techniques for degradation of organic pollutants, which has been used to quickly oxidize $\mathrm{As}(\mathrm{III})$ to $\mathrm{As}(\mathrm{V})$ in recent works ${ }^{[18,19]}$. Due to the low As(III) oxidation rate of PMS at room temperature, there is still a need to activate PMS forming sulfate radicals $\left(\mathrm{SO}_{4}{ }^{-\cdots}\right)$ with high redox potential $(2.5--2.8 \mathrm{~V})$. In peroxosulfate-based AOP systems, sulfate radicals $\left(\mathrm{SO}_{4}{ }^{-\cdots}\right)$ can be formed through activation of PMS by UV, heat and catalysts ${ }^{[20-22]}$. For example, peroxosulfate-based chemicals activated by $\mathrm{UV}$ and $\mathrm{Fe}^{2+}$ rapidly oxidized $\mathrm{As}(\mathrm{III}){ }^{[18,23]}$. As a result of lower energy consumption and its recycling ability, activation of PMS by manganese oxides has attracted a lot of attention compared to UV light, thermal radiation and transition metal ions catalysts such as $\mathrm{Fe}^{2+}, \mathrm{Co}(\mathrm{II}), \mathrm{Cu}(\mathrm{II}), \mathrm{Mn}(\mathrm{II}), \mathrm{Ni}(\mathrm{II})$ and $\mathrm{Ce}(\mathrm{III}){ }^{[21,24-}$ ${ }^{27]}$. For example, Luo et al. reported that manganese oxide/PMS showed high catalytic activity and stability for Acid Orange 7 (AO7) degradation ${ }^{[24]}$. Saputra et al. investigated a manganese oxide/PMS system for phenol degradation, and found that manganese oxide with varying structure and morphology showed different catalytic activity ${ }^{[25]}$. However, to date, no literature has reported whether manganese oxide/PMS systems possess the efficient catalytic activity and stability for rapid As(III) oxidation. Furthermore, the activation mechanism of PMS by manganese oxide for As(III) oxidation is still unknown.

In this paper, As(III) oxidation activity by manganese oxide was tested in the presence of PMS. A remarkable improvement in catalytic activity for fast As(III) oxidation was observed in the manganese oxide/PMS system as compared to manganese oxide or PMS alone. The presence of PMS not only reduced the adverse effects of coexisting ion adsorption on As(III) oxidation by manganese oxide, but also improved the stability of manganese oxide. The mechanism of PMS activation by manganese oxide for As(III) oxidation is also proposed. 


\section{Materials and Methods}

\subsection{Sample preparation}

The manganese oxide sample was prepared by a redox reaction between $\mathrm{KMnO}_{4}$ and $\mathrm{Mn}\left(\mathrm{NO}_{3}\right)_{2}$ at $75{ }^{\circ} \mathrm{C}$ for 48 h. Details of the preparation procedure, which were similar to the literature reported in previous work ${ }^{[28]}$, were as follows. Typically, $3.5190 \mathrm{~g}$ of $\mathrm{Mn}\left(\mathrm{NO}_{3}\right)_{2}$ was added into $80 \mathrm{~mL}$ of distilled water in a $100 \mathrm{~mL}$ beaker, then $3.1608 \mathrm{~g}$ of $\mathrm{KMnO}_{4}$ was dissolved into the above mixture under vigorous magnetic stirring. After $10 \mathrm{~min}$, the beaker was sealed with plastic wrap and subsequently placed into an electric heating oven, heated to $75^{\circ} \mathrm{C}$, and kept at this temperature for $48 \mathrm{~h}$. After the beaker had cooled to room temperature, the resulting precipitates were filtered, washed with distilled water, and dried at $75^{\circ} \mathrm{C}$ for $10 \mathrm{~h}$. In this study, all reagents were of analytical grade without further treatment.

\subsection{Sample characterization}

X-ray diffraction (XRD) patterns were conducted on a Rigaku Dmax X-ray diffractometer using $\mathrm{Cu} \mathrm{K} \alpha$ radiation. The data of Fourier transform infrared (FTIR) and Raman spectra of the samples were collected on a Bruker Vertex 70 spectrophotometer and a LabRAM HR Evolution Raman microscope using a laser light with excitation wavelength at $663 \mathrm{~nm}$, respectively. $\mathrm{Mn}^{2+}$ concentration in solution was measured by inductively coupled plasma/optical emission spectroscopy (ICP/OES, PerkinElmer Optima 4300DV). Mn 2p XPS spectra data were collected on a VG Multilab 2000 X-ray photoelectron spectrometer using Mg K radiation. The collected Mn2p XPS spectra were calibrated by referencing the binding energy of C1s at $284.6 \mathrm{eV}$.

\subsection{As(III) oxidation experiments}

Arsenite oxidation experiments were performed on a rotary oscillator with a stirring speed of $160 \mathrm{rpm}$ at room temperature. Because the PMS is an acidic oxidant, this may lead to a considerable decrease in solution $\mathrm{pH}$ after adding PMS. To eliminate the interference of $\mathrm{pH}$ change during the process of As(III) oxidation, the simulated $0.1 \mathrm{mmol} \mathrm{L}^{-1} \mathrm{As}(\mathrm{III})$ solution was prepared by stepwise diluting a $\mathrm{NaAsO}_{2}$ stock solution using acetate acid/sodium acetate buffer solution ( $\mathrm{pH}$ 6). $\mathrm{NaAsO}_{2}$ stock solution was obtained by dissolving a certain amount This article is protected by copyright. All rights reserved. 
of $\mathrm{NaAsO}_{2}$ in deionized water. To start, manganese oxide and/or PMS were added to the $\mathrm{As}$ (III) solution (50 $\mathrm{mL}$ ) in a $100 \mathrm{~mL}$ Erlenmeyer flask. During As(III) oxidation, $2 \mathrm{~mL}$ of the suspension was removed at specific intervals (e.g., 5, 10, 15, 20, and $30 \mathrm{~min}$ ), mixed with $6 \mathrm{~mL}$ of distilled water, and filtered through $0.22 \mu \mathrm{m}$ cellulose filters. As(V) and total As concentrations $(\mathrm{As}(\mathrm{V})+\mathrm{As}(\mathrm{III}))$ in the solution were analyzed by colorimetric spectrophotometry. The effect of solution $\mathrm{pH}$ on $\mathrm{As}$ (III) oxidation was performed using $\mathrm{HNO}_{3}(0.1$ M) and $\mathrm{NaOH}(0.1 \mathrm{M})$ to adjust the solution $\mathrm{pH}$ to the target value. For the recycling experiment, the used manganese oxide was separated after each cycle, and the next cycle was started by addition of a fresh solution of As(III) and PMS.

\subsection{Analysis}

Arsenate was analyzed using colorimetric spectrophotometry $(\mathrm{As}(\mathrm{V})$ reacts with molybdate forming a blue complex whilst As(III) does not). Detailed detection procedures are described in previous work ${ }^{[15]}$. Total As was determined similar to $\mathrm{As}(\mathrm{V})$ but with the addition of iodine ${ }^{[15]}$. Arsenite was determined by subtracting arsenate from the total As concentration. Arsenite and total As concentrations were determined using hydride generation atomic absorption spectrophotometry if phosphate was present in solution ${ }^{[15]}$.

\section{Results and discussion}

\subsection{Characterization}

Manganese oxide sample was synthesized by a redox reaction between $\mathrm{Mn}\left(\mathrm{NO}_{3}\right)_{2}$ and $\mathrm{KMnO}_{4}$ at $75^{\circ} \mathrm{C}^{[28]}$. $\mathrm{XRD}$ results revealed that manganese oxide possesses a tetragonal cryptomelane structure $\left(\mathrm{KMn}_{8} \mathrm{O}_{16}\right)$ (Fig. 1).

Transmission electron microscopy (TEM) and high-resolution TEM (HRTEM) images exhibited that manganese oxide had nanorod-like morphology with exposed $\{110\}$ facets (Supporting Information Fig. S1). The Brunauer - Emmett - Teller (BET) specific surface area of manganese oxide was $34.1 \mathrm{~m}^{2} \mathrm{~g}^{-1}[28]$. 


\subsection{As(III) oxidation performance}

Batch experimental results for oxidation of As(III) on manganese oxide in the absence of PMS are presented in

Fig. 2A. For manganese oxide at $0.2 \mathrm{~g} \mathrm{~L}^{-1}$, only $41.9 \%$ of $\mathrm{As}(\mathrm{III})$ was oxidized to $\mathrm{As}(\mathrm{V})$ after 30 min, indicating that manganese oxide possesses very low As(III) oxidation activity at low concentration. Increasing the manganese oxide dosage from 0.2 to $0.4,0.8,1.2$, and $1.6 \mathrm{~g} \mathrm{~L}^{-1}$, revealed that As(III) oxidation rate increased from 41.9 to $61.2,82.1,84.4$, and $91.5 \%$, respectively (Fig. 2A). In view of the importance of stability in terms of As(III) oxidation, the recyclability of manganese oxide was examined during reaction between $2.0 \mathrm{~g} \mathrm{~L}^{-1}$ manganese oxide and $0.1 \mathrm{mmol} \mathrm{L}^{-1}$ initial As(III) concentration. As shown in Fig. 2B, compared to the first run (94.1\%), the As(III) oxidation rate of manganese oxide slightly decreased to $82.7 \%$ in the second run. However, in the fourth run, As(III) oxidation had a rapid decrease to $32.0 \%$ after $30 \mathrm{~min}$. The structure of the used manganese oxide was examined by XRD (Fig. 1). Compared to fresh manganese oxide, the position of XRD peaks in the used manganese oxide obviously shifted to high degree, suggesting the structure of manganese oxide may be changed after four successive reactions in this case. This revealed that manganese oxide only acts as an oxidant for As(III) oxidation, rather than a catalyst, and could not be reused.

To improve As(III) oxidation activity and the stability of manganese oxide, As(III) oxidation on manganese oxide in the presence of PMS was investigated. As shown in Fig. 2C, compared to manganese oxide alone $(0.2 \mathrm{~g}$ $\left.\mathrm{L}^{-1}\right)$, As(III) oxidation by manganese oxide in the presence of PMS considerably increased to $95.9 \%$ after 30 min. The chemical oxidants of $\mathrm{H}_{2} \mathrm{O}_{2}$ and $\mathrm{NaClO}$, which had been investigated for As(III) oxidation in previous literature $^{[29-32]}$, were also employed to evaluate their As(III) oxidation activities for comparing with the manganese oxide/PMS system. After 30 min, the As(III) oxidation rates of $\mathrm{H}_{2} \mathrm{O}_{2}$ and $\mathrm{NaClO}$ were 22.6 and $30.3 \%$, respectively (Fig. 2C), which were far lower than that of manganese oxide in the presence of PMS. This result suggested that manganese oxide/PMS can be used as an alternative to chemical oxidants for highly efficient pre-oxidation of As(III). To explain whether an increase in As(III) oxidation on the manganese oxide/PMS system arises from the oxidation ability of PMS, the As(III) oxidation activity of PMS in the absence of manganese oxide was tested (Fig. $2 \mathrm{C}$ and D). At $0.1 \mathrm{mmol} \mathrm{L}^{-1} \mathrm{PMS}$, As(III) oxidation rate was $59.6 \%$ after $30 \mathrm{~min}$. Increasing the PMS concentration to $0.2 \mathrm{mmol} \mathrm{L}^{-1}$, As(III) oxidation rate slightly increased to $63.5 \%$. However, further increments in PMS concentration from 0.2 to 0.8 and $2.0 \mathrm{mmol} \mathrm{L}^{-1}$, revealed that As(III) oxidation rate slightly increased from 63.5 to 73.2 and $78.7 \%$, respectively. This result indicated that As(III) species cannot be sufficiently oxidized to As(V) by PMS only if it was not activated by manganese oxide This article is protected by copyright. All rights reserved. 
even at high concentrations (e.g., $2.0 \mathrm{mmol} \mathrm{L}^{-1}$ ). The stability of the manganese oxide/PMS system for As(III) oxidation was therefore tested (Fig. 2B). After four successive cycles, As(III) oxidation rate was maintained as high as $86.1 \%$ for each run. The $\mathrm{Mn}^{2+}$ release of manganese oxide in the presence of PMS during As(III) oxidation was examined by ICP/ OES analysis. As shown in Supporting Information Fig. S2, the release of $\mathrm{Mn}^{2+}$ concentration within initial 20 min was too low, i. e., below the detection limit $\left(0.005 \mathrm{mg} \mathrm{L}^{-1}\right)$, to be measured by ICP/ OES. After $30 \mathrm{~min}$, a slight $\mathrm{Mn}^{2+}$ release of $0.014 \mathrm{mg} \mathrm{L}^{-1}$ was observed, which was far lower than the stoichiometric release of $\mathrm{Mn}^{2+}$ concentration mediated by As(III) oxidation $\left(5.2 \mathrm{mg} \mathrm{L}^{-1}\right)$. This result indicated that manganese oxide in manganese oxide/PMS system was very stable. The XRD analysis indicated that the phase structure of manganese oxide has no obvious change before and after reaction (Fig. 2). The FTIR and Raman spectra of manganese oxide before and after reaction with As(III) in the presence of PMS was also collected. As shown in Supporting Information Fig. S3, IR absorption peaks at 722, 525, and $471 \mathrm{~cm}^{-1}$, which were assigned to the $\mathrm{Mn}-\mathrm{O}$ vibrations in $\mathrm{MnO}_{6}$ octahedra ${ }^{[33,34]}$, were observed in manganese oxide. After reaction with As(III) in the presence of PMS, the FTIR spectrum of used manganese oxide showed no obvious change compared to fresh manganese oxide. Raman spectrum of the manganese oxide before and after reaction with As(III) in the presence of PMS also has no obvious change (Supporting Information Fig. S4). This result confirmed that the presence of PMS in solution not only promoted As(III) oxidation activity for the manganese oxide, but also enhanced the stability of manganese oxide.

It is well known that both $\mathrm{As}(\mathrm{III})$ and $\mathrm{As}(\mathrm{V})$ coexist in aqueous and soil environment due to varying redox conditions ${ }^{[35,36]}$. Therefore, the effect of competitive adsorption on As(III) oxidation must also be considered in real arsenic polluted wastewater. To determine whether coexisting As(V) affects As(III) oxidation rate on the manganese oxide/PMS system, the effect of $\mathrm{As}(\mathrm{V})$ species in the presence and absence of PMS was investigated by addition of $0.1 \mathrm{mmol} \mathrm{L}^{-1} \mathrm{As}(\mathrm{V})$ in solution (Fig. 3A). For manganese oxide only, following $\mathrm{As}(\mathrm{V})$ addition, As(III) oxidation rate considerably decreased to $30.1 \%$ compared to that without addition. Whereas for the manganese oxide/PMS system, after addition of As(V), As(III) oxidation rate (93.2\%) showed no obvious change compared to that without addition of $\mathrm{As}(\mathrm{V})(96.9 \%)$. This result indicated that the presence of PMS promoted As(III) oxidation on manganese oxide, thus considerably reducing the adverse effect of coexisting $\operatorname{As}(\mathrm{V})$ on $\mathrm{As}(\mathrm{III})$ oxidation. The As(III) oxidation on single PMS in the presence and absence of $\mathrm{As}(\mathrm{V})$ was also evaluated (Fig. 3A). After addition of $0.1 \mathrm{mmol} \mathrm{L}^{-1} \mathrm{As}(\mathrm{V})$, the As(III) oxidation rate of single PMS was 58.5\%, which was nearly the same as that without addition of $\mathrm{As}(\mathrm{V})(59.6 \%)$. This observation indicated that coexisting 
$\mathrm{As}(\mathrm{V})$ ions mainly affected the manganese oxide, thus indirectly altering the As(III) oxidation in the manganese oxide/PMS system.

Phosphate ions commonly exist in natural groundwater and act as competitive ions due to the same structure as As $(V)$. The phosphate ion was therefore used for illustrating the effect of a competitive ion on As(III) oxidation on the manganese/PMS system (Fig. 3B). For manganese oxide only, its As(III) oxidation rate significantly decreased from 41.9 to $28.3 \%$ after addition of $0.1 \mathrm{mmol} \mathrm{L}^{-1}$ phosphate. Addition of phosphate has no obvious effect on As(III) oxidation on single PMS, evidenced by no obvious change of their As(III) oxidation rates before and after addition of phosphate (Fig. 3B). With the manganese oxide/PMS system, As(III) oxidation rate was $94.1 \%$ after adding phosphate, which was reduced by $2.8 \%$ as compared to that without addition. This result once more demonstrated that As(III) can be efficiently oxidized to As(V) with manganese oxide/PMS even in the presence of coexisting ions such as phosphate.

The effect of manganese oxide concentration on As(III) oxidation in the manganese oxide/PMS system was evaluated through changing the manganese oxide dosages from 0.1 to $0.8 \mathrm{~g} \mathrm{~L}^{-1}$. As shown in Fig. 4, As(III) oxidation rate for $0.1 \mathrm{~g} \mathrm{~L}^{-1}$ manganese oxide in the manganese oxide/PMS system was $82.4 \%$ after $30 \mathrm{~min}$. Increasing the manganese oxide dosage to $0.2 \mathrm{~g} \mathrm{~L}^{-1}$ resulted in an $\mathrm{As}(\mathrm{III})$ oxidation rate increase to $95.9 \%$ after $30 \mathrm{~min}$. Increasing the manganese oxide concentration from 0.2 to 0.4 and $0.8 \mathrm{~g} \mathrm{~L}^{-1}$, respectively, demonstrated that As(III) oxidation rates slightly increased from 95.9 to 96.3 and $98.3 \%$ after 30 min, respectively. This result indicates that As(III) oxidation rate does not increase linearly at high manganese oxide concentrations, which may be due to the diffusion of As(III) and PMS which is rate limiting in this case ${ }^{[24]}$. The effect of manganese oxide dosage on As(III) oxidation in the manganese oxide/PMS system was also evaluated at a high initial As(III) concentration of $1.0 \mathrm{mmol} \mathrm{L}^{-1}$. As shown in Supporting Information Fig. S5, As(III) oxidation rates in different manganese oxide/PMS systems at $1.0 \mathrm{mmol} \mathrm{L}^{-1} \mathrm{As}(\mathrm{III})$ concentration were lower than the corresponding values at $0.1 \mathrm{mmol} \mathrm{L}^{-1} \mathrm{As}(\mathrm{III})$ concentration. Increasing manganese oxide dosage from 0.1 to 0.2, 0.4 and $0.8 \mathrm{~g} \mathrm{~L}^{-1}$, respectively, resulted in a slight increase of the As(III) oxidation rate from 26.2 to 29.7, 34.6, and 36.7\%, respectively, suggesting that the PMS concentration is the main limiting factor for As(III) oxidation in this case.

The effect of PMS concentration on As(III) oxidation in the manganese oxide/PMS system was also investigated using a range from 0.01 to $0.2 \mathrm{mmol} \mathrm{L}^{-1}$. As shown in Fig. 5, for PMS at $0.01 \mathrm{mmol} \mathrm{L}^{-1}, \mathrm{As}(\mathrm{III})$ oxidation rate 
was $72.9 \%$ after 30 min. Increasing the PMS concentration to 0.05 and $0.1 \mathrm{mmol} \mathrm{L}^{-1}$ in the reaction system, resulted in As(III) oxidation rates of 84.2 and $95.9 \%$, respectively. This was due to the high PMS concentration in the system, which can produce more active radicals, thus significantly improving As(III) oxidation. However, increasing the PMS concentration to $0.2 \mathrm{mmol} \mathrm{L}^{-1}$ did not result in the same increase in As(III) oxidation. This may be attributed to reaction mechanisms, i. e., at low PMS concentration, As(III) oxidation rate is limited by radical generation, but, at high PMS concentration, As(III) oxidation rate is limited by the contact between radical and arsenite species ${ }^{[24]}$.

The effect of $\mathrm{pH}$ on As(III) oxidation rates in the manganese oxide/PMS system was evaluated by adjusting the solution $\mathrm{pH}$ to $4.3,6.0,7.4,9.2$, and 12.4 , respectively. In acid conditions, higher As(III) oxidation rate occurs (Fig. 6); at $\mathrm{pH} 4.3$, As(III) oxidation rate was $97.1 \%$. When $\mathrm{pH}$ increased from 4.3 to 6.0, 7.4, 9.2, and 12.4, respectively, the As(III) oxidation rates decreased from 97.1 to $95.9,85.0,78.9$, and $75.1 \%$, respectively. A decrease in As(III) oxidation rate at high $\mathrm{pH}$ may be due to an increase in self-dissociation of PMS, which is mainly through non-radical pathways ${ }^{[24,37]}$.

\subsection{A proposed mechanism for As(III) oxidation by PMS activated by manganese oxide}

It is reported that manganese oxide has mixed valences of $\mathrm{Mn}^{3+}$ and $\mathrm{Mn}^{4+[28,38]}$, and PMS can be activated by manganese oxide at different oxidation states to generate abundant $\mathrm{SO}_{5}{ }^{-*}, \mathrm{SO}_{4}^{-{ }^{-}}$, and $\mathrm{HO}$, which has been confirmed by electron paramagnetic resonance (EPR) analysis ${ }^{[26]}$. In addition, $\mathrm{HO}^{\circ}$ can also be produced through the reaction between $\mathrm{SO}_{4}{ }^{-\bullet}$ and $\mathrm{H}_{2} \mathrm{O}^{[24,39]}$. As the redox potential of $\mathrm{SO}_{5}{ }^{-}(1.1 \mathrm{~V}$ at $\mathrm{pH} 7)$ is much lower compared to manganese oxides $\left(\mathrm{E}\left(\mathrm{MnO}_{2} / \mathrm{Mn}^{2+}\right)=1.22 \mathrm{~V}\right), \mathrm{SO}_{4}^{-\bullet}(2.43 \mathrm{~V})$, and $\mathrm{HO}^{-}(2.85 \mathrm{~V}), \mathrm{SO}_{5}^{-\bullet}$ may not be responsible for the As(III) oxidation in this case. This has been proposed in previous reports for degradation of organic pollutants ${ }^{[24,39]}$. To reveal the role of $\mathrm{SO}_{4}{ }^{-\bullet}$ and $\mathrm{HO}^{\bullet}$ for As(III) oxidation in the manganese oxide/PMS system, two classical quenching agents, ethanol (EtOH) and tert-butyl alcohol (TBA) were used for the quenching tests ${ }^{[19,24,37,39]}$. It has been reported that EtOH and TBA show sufficient quenching performance for $\mathrm{HO}^{\bullet}$ radicals, i.e., their reaction rates with $\mathrm{HO}^{\circ}$ are $1.2 \times 10^{9} \sim 2.8 \times 10^{9} \mathrm{M}^{-1} \mathrm{~s}^{-1}$ and $3.8 \times 10^{8} \sim 7.6 \times 10^{8} \mathrm{M}^{-1} \mathrm{~s}^{-1}$, respectively ${ }^{[39,40]}$. However, the reaction rate of $\mathrm{EtOH}$ with $\mathrm{SO}_{4}{ }^{--}$is $1.6 \times 10^{7} \sim 7.7 \times 10^{7}$, which is more rapid than that of TBA $\left(4.0 \times 10^{5} \sim 9.1 \times 10^{5} \mathrm{M}^{-1} \mathrm{~s}^{-1}\right)^{[40]}$. Thus, we can distinguish the role of $\mathrm{SO}_{4}^{-{ }^{-}}$and $\mathrm{HO}^{\bullet}$ for As(III) oxidation using both EtOH and TBA as quenching agents. As shown in Fig. 7, after addition of 1.0 This article is protected by copyright. All rights reserved. 
$\mathrm{mmol} \mathrm{L} \mathrm{L}^{-1} \mathrm{EtOH}$, the As(III) oxidation rate in the manganese oxide/PMS system was reduced by $13.3 \%$ compared to that without addition. More addition of EtOH (2.0 mM) further decreased As(III) oxidation rate, which was reduced by $25.6 \%$. However, after addition of 1.0 and $2.0 \mathrm{mmol} \mathrm{L}^{-1} \mathrm{TBA}$, respectively, the As(III) oxidation rate slightly decreased to 94.2 and $93.0 \%$, respectively. Since the effect of TBA on As(III) oxidation is weaker than that of EtOH, sulfate radicals are the dominant active species for As(III) oxidation. In addition, $\mathrm{HO}^{\circ}$ radicals might also exist, but they play a minor role compared to sulfate radicals.

Based on the above analysis, the proposed activation process of PMS by manganese oxide was as follows. Firstly, the $\mathrm{SO}_{4}^{-{ }^{-}}$and $\mathrm{HO}^{\circ}$ radicals were produced by the reduction of high-valent state of $\mathrm{Mn}$ species in manganese oxide, the generated low-valent $\mathrm{Mn}$ species was subsequently re-oxidized by $\mathrm{HSO}_{5}{ }^{--}$. Therefore, we speculated that the redox pair of $\mathrm{Mn}^{3+} / \mathrm{Mn}^{4+}$ in manganese oxide may play an important role in activation of PMS to generate highly active radicals, thus significantly promoting the activity and stability of manganese oxide for As(III) oxidation. To illustrate the role of Mn species in PMS activation, the XPS spectra of manganese oxide in the presence of PMS were detected before and after four successive experiments for As(III) oxidation. For comparison, the Mn2p XPS of manganese oxide after four successive experiments in the absence of PMS was also collected. For manganese oxide/PMS without As(III), three peaks at $\sim 640.5, \sim 641.9$ and $\sim 643.0 \mathrm{eV}$ were deconvoluted from its $\mathrm{Mn} 2 \mathrm{p} 3 / 2$ spectra, which were attributed to $\mathrm{Mn}^{2+}, \mathrm{Mn}^{3+}$, and $\mathrm{Mn}^{4+}$ species, respectively ${ }^{[41]}$. The calculated $\mathrm{Mn}^{3+} / \mathrm{Mn}^{4+}$ and $\mathrm{Mn}^{2+} / \mathrm{Mn}^{4+}$ atomic ratios in manganese oxide/PMS without As(III) were 0.68 and 0.12, respectively. Remarkably, after four successive reactions with As(III), the $\mathrm{Mn}^{3+} / \mathrm{Mn}^{4+}(0.65)$ and $\mathrm{Mn}^{2+} / \mathrm{Mn}^{4+}(0.14)$ atomic ratios in manganese oxide/PMS were very close to those of manganese oxide/PMS without As(III) (Fig. 8). However, for single manganese oxide, after four successive reactions with $\mathrm{As}(\mathrm{III})$, the $\mathrm{Mn}^{3+} / \mathrm{Mn}^{4+}$ and $\mathrm{Mn}^{2+} / \mathrm{Mn}^{4+}$ atomic ratios increased to 0.99 and 0.29 , respectively, suggesting that high valence of $\mathrm{Mn}^{4+}$ partially transformed to $\mathrm{Mn}^{3+}$ and/or $\mathrm{Mn}^{2+}$ species in this case. This result indicated that manganese oxide was more stable for As(III) oxidation in the presence of PMS.

Based on quenching test results as well as XPS analysis, the proposed mechanism of PMS activation by manganese oxide for As(III) oxidation can be described as follows: 


$$
\begin{aligned}
& \equiv \mathrm{Mn}(\mathrm{IV})+\mathrm{HSO}_{5}{ }^{-} \rightarrow \equiv \mathrm{Mn}(\mathrm{III})+\mathrm{SO}_{4}{ }^{-\bullet}+\mathrm{OH}^{-}(1) \\
& \equiv \mathrm{Mn}(\mathrm{IV})+\mathrm{HSO}_{5}{ }^{-} \rightarrow \equiv \mathrm{Mn}(\mathrm{III})+\mathrm{SO}_{4}{ }^{2-}+\mathrm{HO}^{\bullet}(2) \\
& \equiv \mathrm{Mn}(\mathrm{III})+\mathrm{HSO}_{5}{ }^{-} \rightarrow \equiv \mathrm{Mn}(\mathrm{IV})+\mathrm{SO}_{5}{ }^{-\bullet}+\mathrm{H}^{+}
\end{aligned}
$$

Firstly, PMS is activated by high-valent Mn species to generate $\mathrm{SO}_{4}^{-\bullet}, \mathrm{HO}$ radicals, and low-valent Mn species. Abundant $\mathrm{SO}_{4}^{-\bullet}$ radicals are rapidly depleted by reacting with $\mathrm{As}(\mathrm{III})$. Though $\mathrm{HO}^{\bullet}$ radicals have a slow reaction rate compared to $\mathrm{SO}_{4}^{-\cdot}$ radicals, some of the $\mathrm{HO}^{\bullet}$ produced also participated in the As(III) oxidation. At the same time, the reduced manganese oxide $(\equiv \mathrm{Mn}(\mathrm{III}))$ can react with PMS and subsequently recover to its original state $(\equiv \mathrm{Mn}(\mathrm{IV}))$. Remarkably, the structural Mn in manganese oxide may also participate in the reaction once the addition amount of PMS in the manganese oxide/PMS system was too little to generate enough $\mathrm{SO}_{4}{ }^{-\bullet}$ and $\mathrm{HO}^{\bullet}$ radicals for As(III) oxidation. Therefore, the mechanism involved structural Mn for As(III) oxidation will be investigated in future work.

\section{Conclusion}

In summary, manganese oxide was employed for As(III) oxidation by the diverse activation of PMS. Arsenite oxidation revealed that the manganese oxide/PMS system had higher As(III) oxidation activity compared to manganese oxide or PMS only. The presence of PMS in solution not only reduced the adverse effect of competitive adsorption on As(III) oxidation, but also improved the stability of manganese oxide. Increasing manganese oxide and PMS concentrations led to an increase in As(III) oxidation, but with the increase of $\mathrm{pH}$, As(III) oxidation rate decreased. Quenching tests revealed that sulfate radicals are the main active species responsible for As(III) oxidation. The present work provides a practical approach to improving As(III) oxidation activity and stability of manganese oxide by adding PMS to arsenic-polluted water. 


\section{Acknowledgments}

This work was supported by National Key Research and Development Program of China (2018YFC1800305, 2018YFC1800302), Hubei Provincial Natural Science Foundation of China (2018CFB627), Fundamental Research Funds for the Central Universities (No. 2662017QD013), and Major Projects for Special Technology Innovation of Hubei Province (2019AAA012).

The authors have declared no conflict of interest.

\section{References}

[1] S. Fendorf, H. A. Michael, A. Van Geen, Science 2010, 328, 1123.

[2] H. A. Michael, Science 2013, 341, 852.

[3] P. R. Hunter, A. M. Macdonald, R. C. Carter, PLoS Med 2010, 7, 1.

[4] J. Ventura-Lima, M. R. Bogo, J. M. Monserrat, Ecotoxicol. Environ. Saf. 2011, 74, 211.

[5] P. Mondal, S. Bhowmick, D. Chatterjee, A. Figoli, B. Van der Bruggen, Chemosphere 2013, $92,157$.

[6] M. Wang, W. Tan, X. Feng, L. K. Koopal, M. Liu, F. Liu, Mater. Lett. 2012, 77, 60.

[7] B. A. Manning, S. E. Fendorf, B. Bostick, D. L. Suarez, Environ. Sci. Technol. 2002, 36, 976.

[8] B. J. Lafferty, M. Ginder-Vogel, D. L. Sparks, Environ. Sci. Technol. 2011, 45, 9218.

[9] H. W. Nesbitt, G. W. Canning, G. M. Bancroft, Geochim. Cosmochim. Acta 1998, 62, 2097-2110.

[10] M. Villalobos, I. N. Escobar-Quiroz, C. Salazar-Camacho, Geochim. Cosmochim. Acta 2014, $125,564$.

[11] S. Ouvrard, P. de Donato, M. O. Simonnot, S. Begin, J. Ghanbaja, M. Alnot, Y. B. Duval, F. Lhote, O. Barres, M. Sardin, Geochim. Cosmochim. Acta 2005, 69, 2715.

[12] X. J. Li, C. S. Liu, F. B. Li, Y. T. Li, L. J. Zhang, C. P. Liu, Y. Z. Zhou, J. Hazard. Mater. 2010, $173,675$. 
[13] J. N. Moore, J. R. Walker, T. H. Hayes, Clays Clay Miner. 1990, 38, 549.

[14] J. Hou, Y. Xiang, D. Zheng, Y. Li, S. Xue, C. Wu, W. Hartley, W. Tan, Chem. Eng. J. 2017, $327,235$.

[15] J. Hou, J. Luo, Z. Hu, Y. Li, M. Mao, S. Song, Q. Liao, Q. Li, Chem. Eng. J. 2016, 306, 506.

[16] S. J. Parikh, B. J. Lafferty, T. G. Meade, D. L. Sparks, Environ. Sci. Technol. 2010, 44, 3772.

[17] J. Hou, Z. Sha, W. Hartley, W. Tan, M. Wang, J. Xiong, Y. Li, Y. Ke, Y. Long, S. Xue, Environ. Pollut. $2018,238,524$.

[18] J. Xu, W. Ding, F. Wu, G. Mailhot, D. Zhou, K. Hanna, Appl. Catal. B Environ. 2016, 186, 56.

[19] Z. Wang, R. T. Bush, L. A. Sullivan, C. Chen, J. Liu, Environ. Sci. Technol. 2014, 48, 3978.

[20] Z. Huang, H. Bao, Y. Yao, W. Lu, W. Chen, Appl. Catal. B Environ. 2014, 154-155, 36.

[21] R. H. Waldemer, P. G. Tratnyek, R. L. Johnson, J. T. Nurmi, Environ. Sci. Technol. 2007, 41, 1010.

[22] O. S. Furman, A. L.Teel, R. J. Watts, Environ. Sci. Technol. 2010, 44, 6423.

[23] B. Neppolian, E. Celik, H. Choi, Water Res. 2008, 42, 6179.

[24] S. Luo, L. Duan, B. Sun, M. Wei, X. Li, A. Xu, Appl. Catal. B Environ. 2015, 164, 92.

[25] E. Saputra, S. Muhammad, H. Sun, H. M. Ang, M. O. Tadé, S. Wang, Appl. Catal. B Environ. 2013, 142$143,729$.

[26] Y. Wang, H. Sun, H. M. Ang, M. O. Tadé, S. Wang, Appl. Catal. B Environ. 2015, 164, 159.

[27] H. Liang, H. Sun, A. Patel, P. Shukla, Z. H. Zhu, S. Wang, Appl. Catal. B Environ. 2012, 127, 330.

[28] J. Hou, J. Luo, S. Song, Y. Li, Q. Li, Chem. Eng. J. 2017, 315, 159.

[29] M. Pettine, L. Campanella, F. J.Millero, Geochim. Cosmochim. Acta 1999, 63, 2727.

[30] M. Lescano, C. Zalazar, A. Cassano, Chem. Eng. J. 2012, 211, 360.

[31] L. Sun, R. Liu, S. Xia, Y. Yang, G. Li, Desalination 2009, 243, 122. 
[32] A. Li, J. Luo, W. Xu, T. Pan, Desalin. Water Treat. 2015, 55, 1285.

[33] B. Hu, C. Chen, S. J. Frueh, L. Jin, R. Joesten, S. L. Suib, J. Phys. Chem. C 2010, 114, 9835.

[34] Y. Liu, J. Hou, Mater. Res. Bull. 2019, 118, 110497.

[35] J. Gorny, G. Billon, L. Lesven, D. Dumoulin, B. Madé, C. Noiriel, Sci. Total Environ. 2015, 505, 423.

[36] P. L. Smedley, D. G. Kinniburgh, Appl. Geochemistry 2002, 17, 517.

[37] A. Rastogi, S. R. Al-Abed, D. D. Dionysiou, Appl. Catal. B Environ. 2009, 85, 171.

[38] J. Hou, Y. Li, L. Liu, L. Ren, X. Zhao, J. Mater. Chem. A 2013, 1, 6736.

[39] Y. Ding, L. Zhu, N. Wang, H. Tang, Appl. Catal. B Environ. 2013, 129, 153.

[40] G. V Buxton, C. L. Greenstock, W. P. Helman, A. B. Ross, J. Phys. Chem. Ref. Data 1988, $17,513$.

[41] V. P. Santos, M. F. R. Pereira, J. J. M. Órfão, J. L. Figueiredo, Appl. Catal. B Environ. 2010, $99,353$. 
Figure 3. As(III) oxidation on single Mn oxide, PMS, and Mn oxide/PMS system before and after addition of $0.1 \mathrm{mmol} \mathrm{L}^{-1} \mathrm{As}(\mathrm{V})(\mathrm{A})$ and phosphate (B) at $\mathrm{pH}$ 6: Mn oxide concentration of $0.2 \mathrm{~g} \mathrm{~L}^{-1}$, PMS of $0.1 \mathrm{mmol}$ $\mathrm{L}^{-1}$, and As(III)/ phosphate of $0.1 \mathrm{mmol} \mathrm{L}^{-1}$.

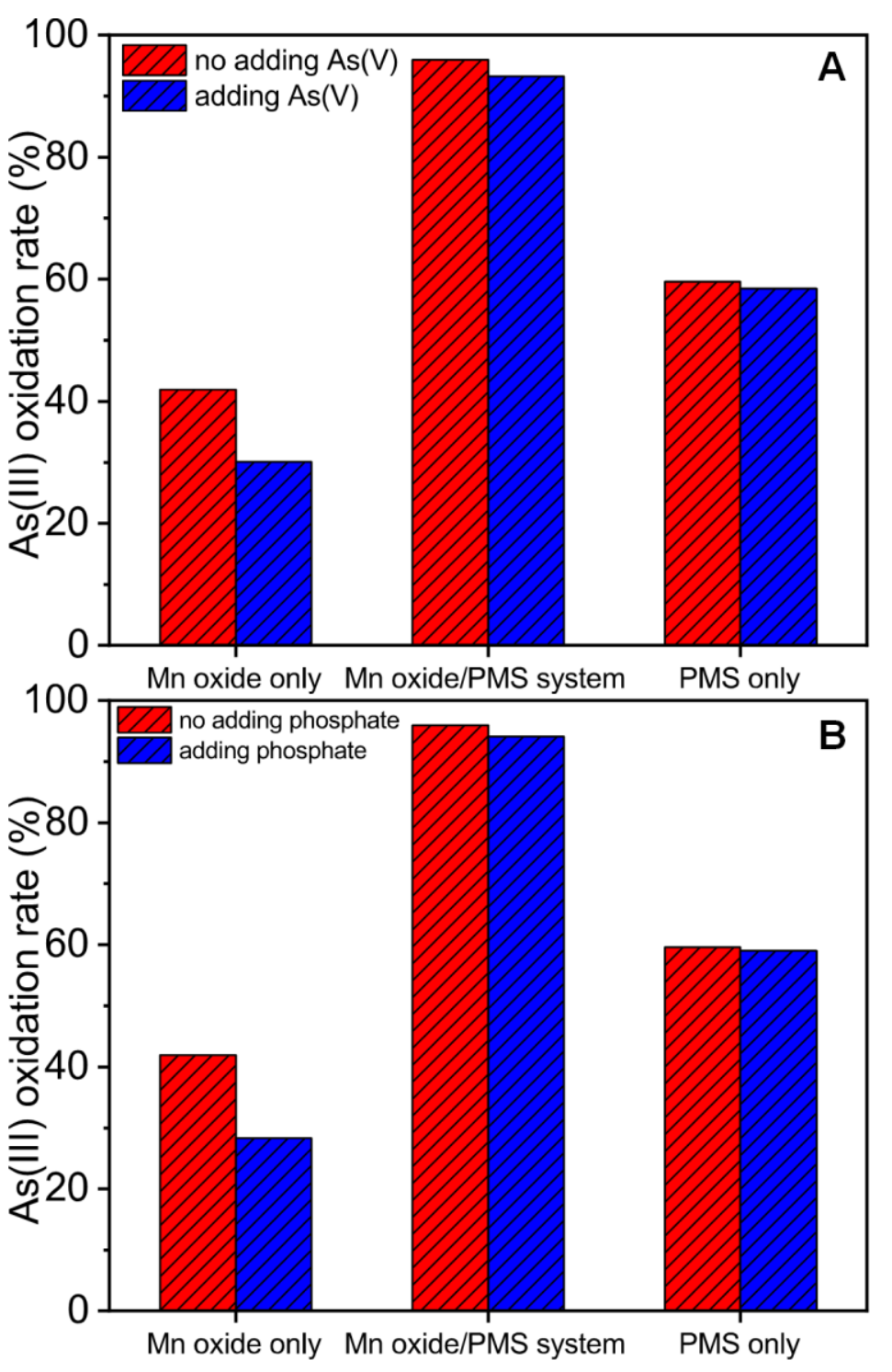


Figure 4. The effect of manganese dosage on As(III) oxidation by the manganese oxide/PMS system at $\mathrm{pH} 6$ : PMS of $0.1 \mathrm{mmol} \mathrm{L}^{-1}$ and As(III) of $0.1 \mathrm{mmol} \mathrm{L}^{-1}$.

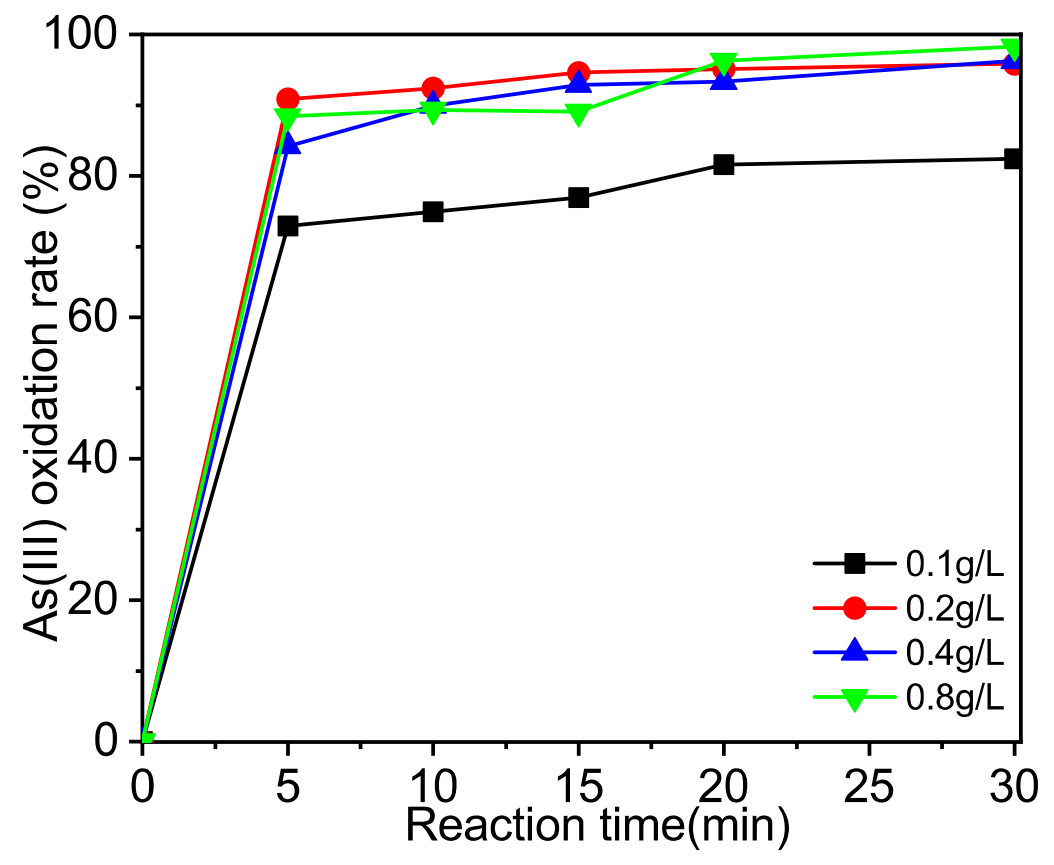

Figure 5. The effect of PMS concentration on As(III) oxidation by the manganese oxide/PMS system at $\mathrm{pH} 6$ : manganese oxide of $0.2 \mathrm{~g} \mathrm{~L}^{-1}$ and As(III) of $0.1 \mathrm{mmol} \mathrm{L-}^{-1}$.

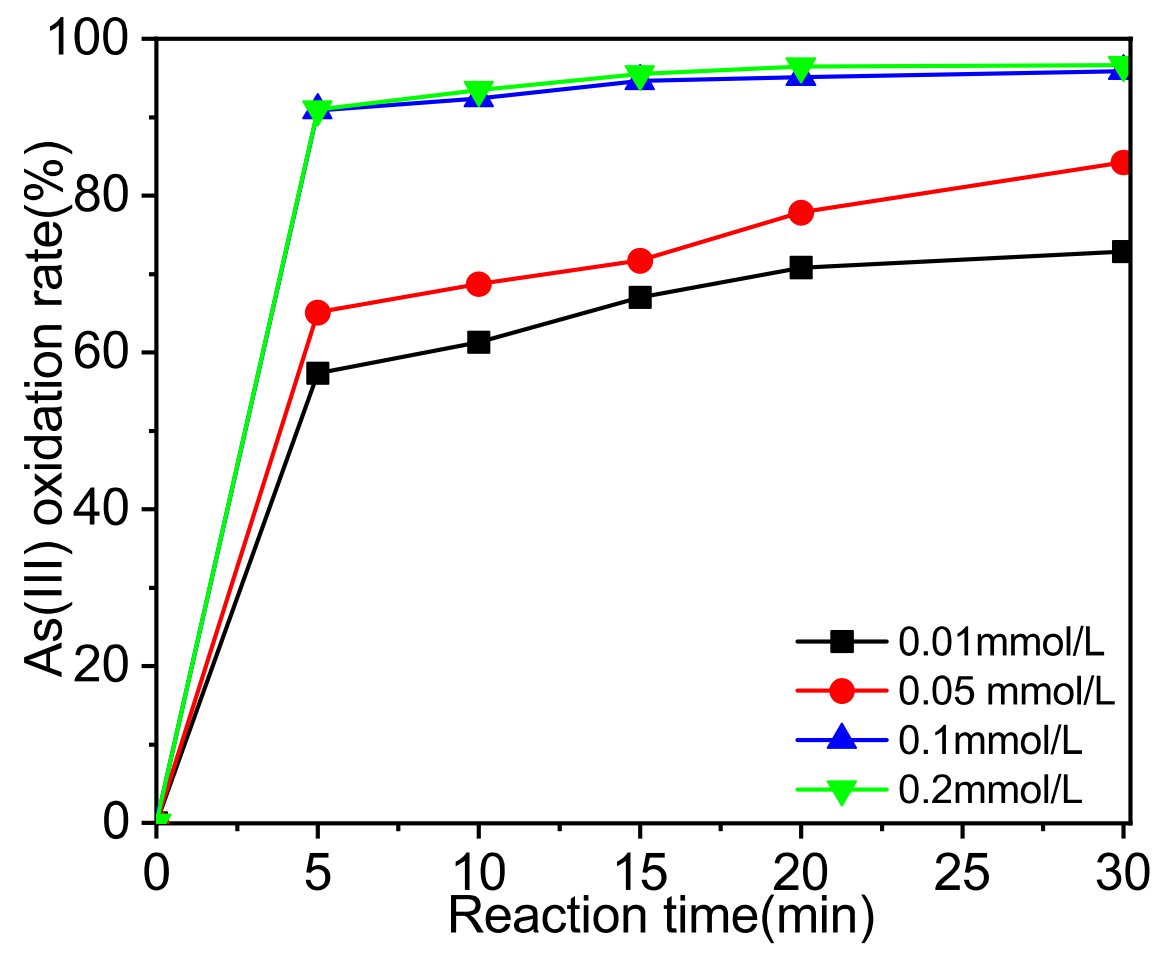

This article is protected by copyright. All rights reserved. 
Figure 6. The effect of reaction $\mathrm{pH}$ on $\mathrm{As}(\mathrm{III})$ oxidation by the manganese oxide/PMS system at $\mathrm{pH} 6$ : manganese oxide of $0.2 \mathrm{~g} \mathrm{~L}^{-1}$, PMS of $0.1 \mathrm{mmol} \mathrm{L}^{-1}$, and As(III) of $0.1 \mathrm{mmol} \mathrm{L}^{-1}$.

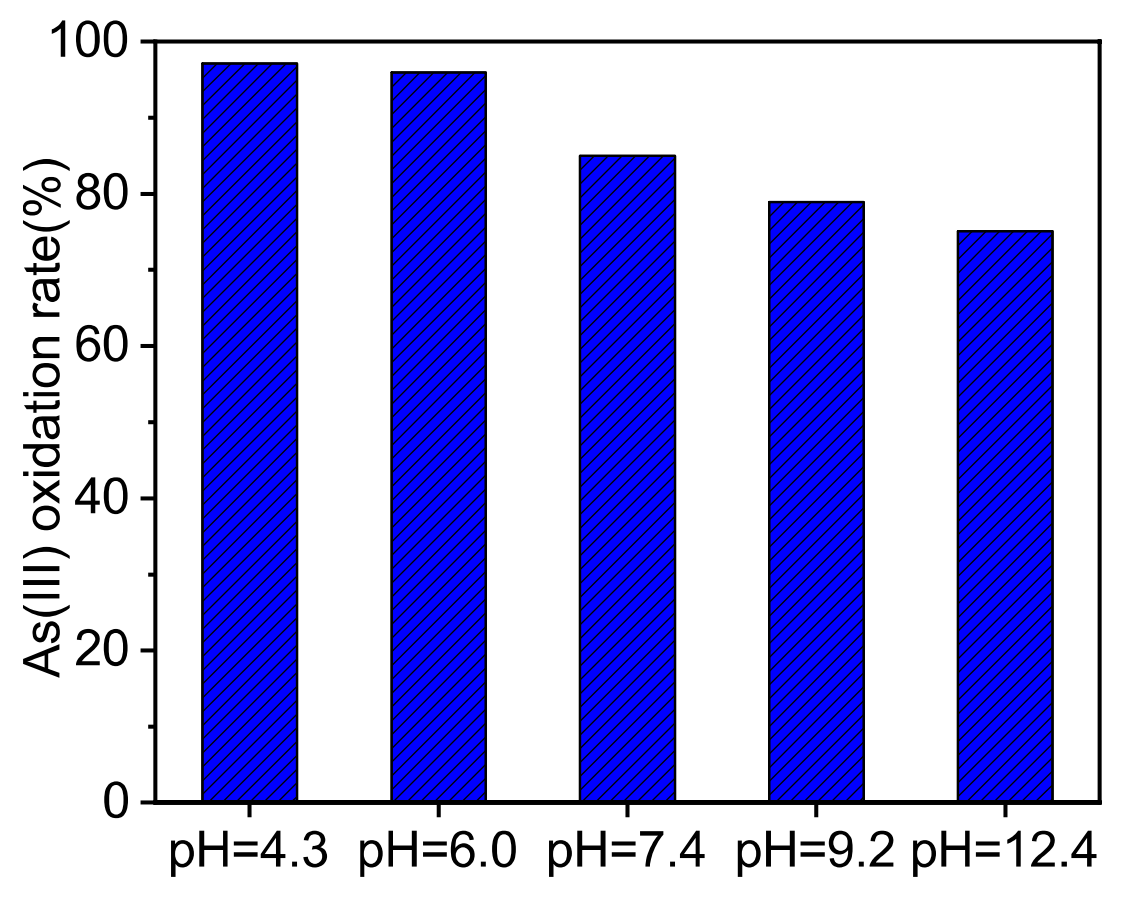

Figure 7. As(III) oxidation by the manganese oxide/PMS system before and after addition of quenching agents EtOH $\left(1.0 \mathrm{mmol} \mathrm{L}^{-1}\right)$ and TBA $\left(1.0 \mathrm{mmol} \mathrm{L}^{-1}\right)$ after $30 \mathrm{~min}$ : As(III) of $0.1 \mathrm{mmol} \mathrm{L}{ }^{-1}$, manganese oxide of $0.2 \mathrm{~g}$ $\mathrm{L}^{-1}$, and PMS of $0.1 \mathrm{mmol} \mathrm{\textrm {L } ^ { - 1 }}$.

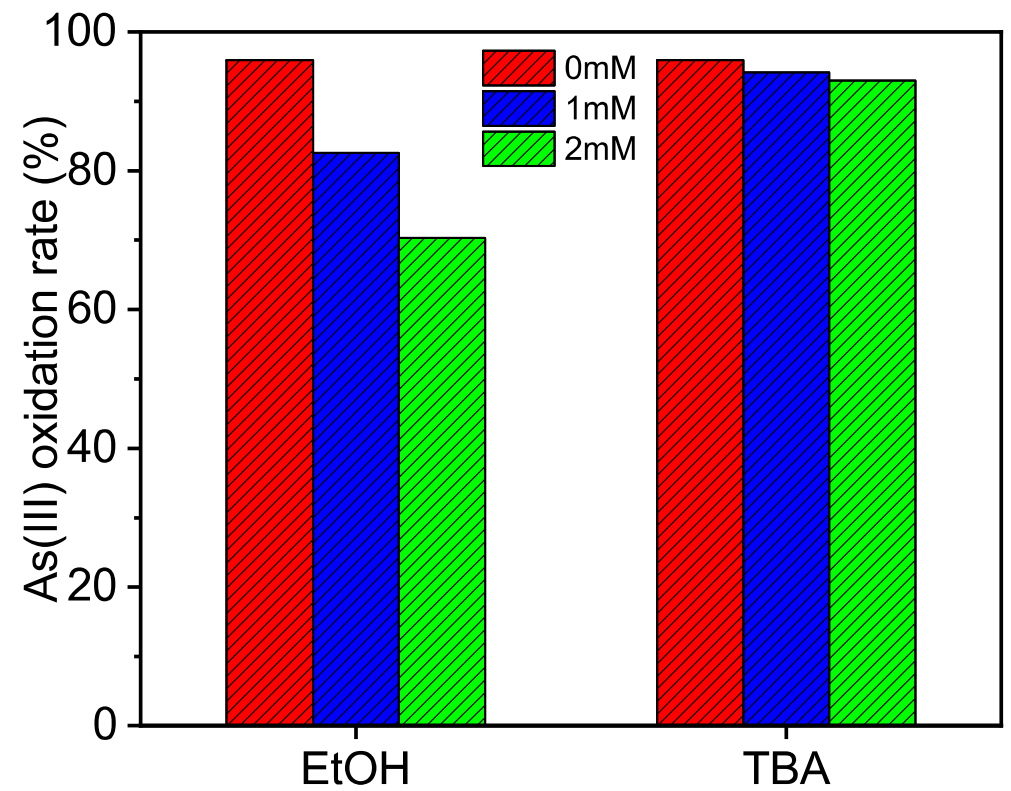

This article is protected by copyright. All rights reserved. 
Graphical abstract

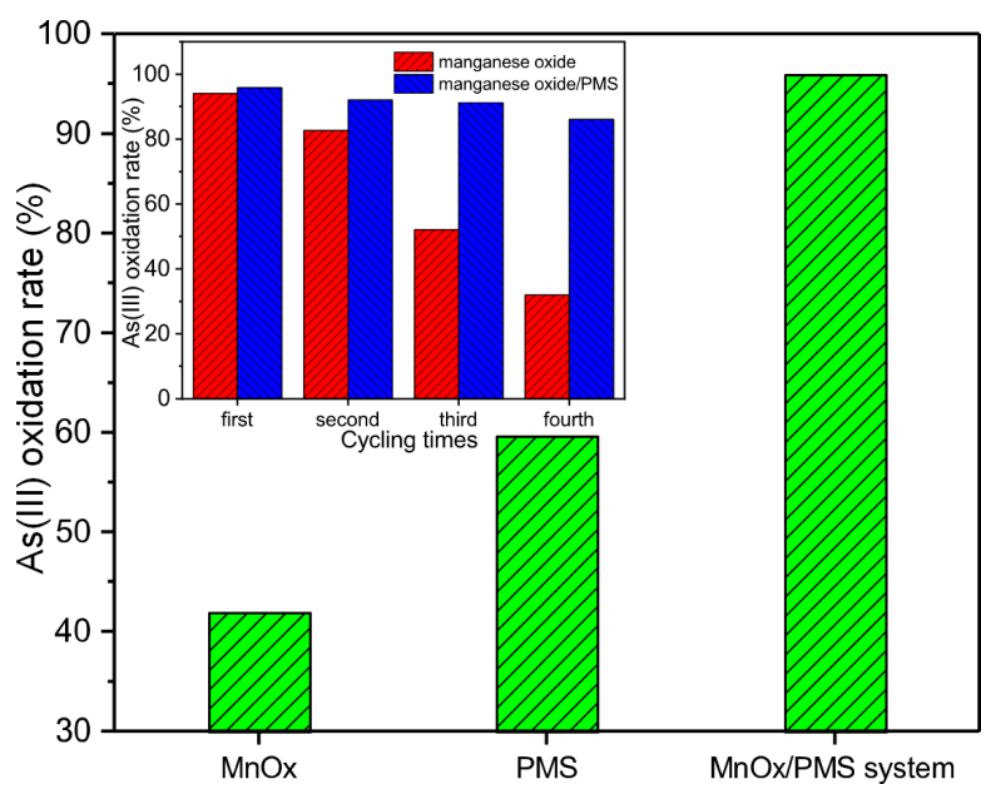

The As(III) oxidation activity by $\mathrm{Mn}$ oxide was tested in the presence of peroxymonosulfate (PMS). The result shows that addition of PMS not only reduced the adverse effects of coexisting ions on As(III) oxidation by Mn oxide, but also improved its stability. This study provides a practical approach for treating arsenic-containing water. 